\title{
Granzyme F induces a novel death pathway characterized by Bid-independent cytochrome $c$ release without caspase activation
}

\author{
$L$ Shi ${ }^{1}, \mathrm{~L} \mathrm{Wu}{ }^{1}, \mathrm{~S}$ Wang $^{1}$ and $Z$ Fan $^{\star, 1}$
}

Granzyme $F(G z m F)$ belongs to a unique group of granzymes in mice. Murine GzmF is highly expressed in NK3.1 cells and in lymphokine-activated killer (LAK) cells. However, the manner in which GzmF works in granule-mediated cytolysis is unknown. In this study, we first demonstrated that GzmF causes a novel cell death pathway. The death is characterized by an externalization of phosphatidylserine, by nuclear condensation, mitochondrial damage, cytochrome $c$ (cyt $c$ ) release, caspase inactivation and single-stranded DNA nicking. GzmF-induced chromatin was incompletely condensed and segmented at the nuclear periphery. Cellular organelles were damaged and the cytoplasm showed an extensive vacuolization that is reminiscent of necroptosis. GzmF can cause rapid mitochondrial swelling, depolarization and reactive oxygen species accumulation. GzmF-induced death does not involve caspase activation, Bid cleavage or activation of DNA nickase NM23H1. GzmF-silenced LAK cells showed reduced cytotoxicity against caspase-inhibited target tumor cells. Moreover, cyt $c$ release is independent of Bid or Bax/Bak. We further showed that GzmF impairs mitochondrial electron transport to abolish ATP generation. ATP decline may contribute to a failure of apoptosome formation, leading to caspase inactivation.

Cell Death and Differentiation (2009) 16, 1694-1706; doi:10.1038/cdd.2009.101; published online 31 July 2009

Perforin (PFP)/Granzymes (Gzms) of cytotoxic lymphocytes have a major role in the clearance of tumor cells and virusinfected target cells. ${ }^{1,2}$ A large number of Gzms have been identified in mice (A, B, C, D, E, F, G, K, M and N), but only GzmA and $G z m B$ have been extensively studied. ${ }^{3} \mathrm{GzmB}$ is an Aspase that cleaves after Asp residue of physiological substrates. It activates several caspases and directly cleaves some death substrates, such as the inhibitor of caspaseactivated DNase (ICAD), to mediate classical apoptosis with double-stranded DNA fragmentation. ${ }^{4} \mathrm{GzmB}$ can process Bid to truncated $\mathrm{Bid}$ (tBid) that translocates into the mitochondria to cause cytochrome $c$ (cyt $c$ ) release, which leads to apoptosome assembly and caspase cascade activation. ${ }^{5}$ GzmA is a tryptase that cleaves its specific substrates after basic residues Arg or Lys. GzmA mediates single-stranded DNA nicking and caspase-independent death through the destruction of an endoplasmic reticulum-associated SET complex. ${ }^{6,7}$ Murine GzmC was reported to trigger a caspase-independent death program that differs from GzmA or GzmB. ${ }^{8}$ Recently, several groups have demonstrated that human GzmK, GzmH and GzmM mediate non-redundant death pathways. ${ }^{9-13}$

Natural murine GzmF was first isolated from CTL granules by Masson and Tschopp in 1987 and the gene was cloned by Jenne et al. ${ }^{14,15}$ Murine GzmF belongs to the third group (group 3) of Gzms, including GzmD, E, F, G, L and N. ${ }^{3,16}$ Members of group $3 \mathrm{Gzms}$ show high nucleotide similarity and are physically clustered with GzmB and GzmC genes at chromosome 14 of mice. However, the role of GzmF in granule-mediated cell death has not been defined.

Granzyme F is highly expressed in NK3.1 cells and in lymphokine-activated killer (LAK) cells derived from splenocytes. ${ }^{17} \mathrm{~A}$ recent study showed that GzmB locus knockout mice (GzmB ${ }^{-1-} /+$ PGK-neo) with a significant reduction of GzmF and GzmC expression displayed a more severe defect in killing tumor cells than did mice deficient in GzmB only. ${ }^{18}$ These findings suggest that GzmF and GzmC may have important roles in the cytotoxic functions of killer lymphocytes. In this study, we demonstrated that GzmF causes a novel cell death pathway. The death is characterized by phosphatidylserine (PS) externalization, nuclear condensation, mitochondrial damage, cyt $c$ release, caspase inactivation and singlestranded DNA nicking. Moreover, cyt $c$ release is independent of Bid or Bax/Bak. We further showed that GzmF impairs mitochondrial electron transport to abolish ATP generation. Intracellular ATP decline may contribute to a failure of apoptosome formation, leading to caspase inactivation.

Results

GzmF induces cell death. Murine GzmF cDNA was cloned from a mouse thymus and subcloned into pET26b. Recombinant GzmF was expressed in E. coli and refolded from

\footnotetext{
${ }^{1}$ National Laboratory of Biomacromolecules and Center for Infection and Immunity, Institute of Biophysics, Chinese Academy of Sciences, Beijing 100101, China *Corresponding author: Z Fan, National Laboratory of Biomacromolecules and Center for Infection and Immunity, Institute of Biophysics, Chinese Academy of Sciences, Beijing 100101, China. Tel: 010-64888457; Fax: 010-64871293; E-mail: fanz@moon.ibp.ac.cn

Keywords: granzyme F; cytochrome $c$ release; caspase inactivation; mitochondrial damage; ATP decline

Abbreviations: Gzm, granzyme; S-AGzmF, Ser195AlaGzmF; Ad, replication-deficient adenovirus type V; PFP, perforin; SLO, streptolysin O; MEF, mouse embryonic fibroblast; STP, staurosporine; cyt $c$, cytochrome $c$; LAK, lymphokine-activated killer; shRNA, small hairpin RNA; AV, annexin V; PI, propidium iodide; ROS, reactive oxygen species; ICAD, inhibitor of caspase-activated DNase; Apaf-1, apoptotic protease-activating factor 1

Received 16.12.08; revised 17.6.09; accepted 30.6.09; Edited by J Tschopp; published online 31.7.09
} 
inclusion bodies as previously described. ${ }^{19}$ The inactive counterpart, Ser195AlaGzmF (S-AGzmF), was generated by a point mutation of the active site, Ser 195, to Ala. The Gzms were purified with nickel chelation columns, followed by cation exchange chromatography. Proteins were verified by mass spectrometry (data not shown) and purity (>95\%) was monitored by Coomassie brilliant blue staining (Figure 1a left panel).

A previous report showed that native GzmF had activity toward Suc-Phe-Leu-Phe-Sbzl. ${ }^{20}$ Recombinant GzmF was able to cleave the synthetic substrate, Suc-Phe-Leu-PhepNA, and showed strong enzymatic activity (Figure 1a right panel), which was in agreement with the previous report. The enzymatic inactive mutant GzmF (S-AGzmF) had no activity toward Suc-Phe-Leu-Phe-pNA. We also utilized a set of synthetic substrates to define the catalytic specificity of recombinant GzmF. GzmF had no activity against other synthetic substrates, including AAF-pNA (substrate for tripeptidylpeptidase I and II), AAPF-pNA (substrate for cathepsin G), PTSY-pNA (substrate for GzmH), AAPL-pNA (substrate for GzmM), IETD-AFC (substrate for GzmB), PheArg-AMC (substrate for cathepsin L) and Z-Arg-Arg-AMC (substrate for cathepsin $\mathrm{B}$ ), as well as against a series of caspase substrates, VDVAD-AFC, DEVD-AFC and LEHDAFC (Figure 1a right panel, data not shown).

To determine the function of GzmF, Gzm delivery agent replication-deficient adenovirus type $\mathrm{V}(\mathrm{Ad})$ was used to deliver GzmF into target tumor cells. The adenovirusmediated delivery of Gzms was developed by Froelich laboratory and this system proved useful for loading Gzms into target tumor cells. 9,21,22 GzmF was loaded into ${ }^{51} \mathrm{Cr}$-labeled Yac-1 cells with an optimal dose of Ad for a $6 \mathrm{~h}$ specific cytotoxicity assay. We found that GzmF caused dramatic cytolysis $(56.9 \pm 9.9 \%$ ) (Figure $1 \mathrm{~b})$. GzmB/Ad- or GzmC/Ad-treated cells were used as positive controls (GzmB, $58.3 \pm 3.7 \%$; GzmC, $42.6 \pm 14.3 \%$ ). In contrast, cells treated with $\mathrm{Ad}$ and GzmF alone, or with S-AGzmF/Ad, displayed only background levels of ${ }^{51} \mathrm{Cr}$ release. It indicates that $\mathrm{GzmF}$ was capable of inducing target cell death and its enzymatic activity is required. These data are representative of at least three separate experiments.

To further characterize the death features of GzmF-induced death, PS externalization was detected by staining with Fluoscoupled Annexin V (AV) and propidium iodide (PI). PS externalization is an early hallmark of apoptotic cells. At a low concentration of $0.25 \mu \mathrm{M}$, GzmF was able to cause PS externalization of target Yac-1 cells (46.5\%) (Figure 1c). PS externalization reached a peak level at a concentration of $0.7 \mu \mathrm{M} \quad(0.5 \mu \mathrm{M}, 54.3 \% ; 0.7 \mu \mathrm{M}, 66.1 \% ; 0.85 \mu \mathrm{M}, 64.6 \%$; $1.0 \mu \mathrm{M}, 66.8 \%)$. Late-stage dead cells $\left(\mathrm{AV}^{+} / \mathrm{PI}^{+}\right)$kinetically augmented with increasing concentrations of GzmF $(0.25 \mu \mathrm{M}$, $23.8 \% ; 0.5 \mu \mathrm{M}, 34.1 \% ; 0.7 \mu \mathrm{M}, 46.1 \% ; 0.85 \mu \mathrm{M}, 50.1 \%$; $1.0 \mu \mathrm{M}, 58.4 \%$ ). Strikingly, at a concentration of $1.0 \mu \mathrm{M}$, the number of single $\mathrm{AV}^{+}$cells was much less than that of $\mathrm{AV}^{+} / \mathrm{PI}^{+}$(8.4 versus $\left.58.4 \%\right)$. These observations are reminiscent of GzmC (18.1 versus 60\%). Staurosporine (STP)-treated cells were used as typical apoptosis control. In contrast, GzmB induced much higher single $\mathrm{AV}^{+}$cells than did $\mathrm{AV}^{+} / \mathrm{PI}^{+}$(58.2 versus $\left.27.7 \%\right)$, which is one of the classical apoptotic features (Figure 1c, d). Mock-treated, GzmF and Ad alone, or S-AGzmF/Ad-treated cells showed only background death $\left(\mathrm{AV}^{+} / \mathrm{PI}^{+}<8 \%\right)$. These data represent at least three independent experiments. Similar results were obtained using human Jurkat cells (data not shown). These data suggest that GzmF induces a novel cell death pathway that is distinct from typical apoptosis.

\section{Knockdown of GzmF expression by RNAi reduces LAK} cell-mediated caspase-independent cytotoxicity. To determine the patterns of Gzms expression during LAK cell activation, we assessed mRNA levels of Gzms at different times using quantitative RT-PCR. As shown in Figure 2a, GzmB mRNA contents increased with IL-2 stimulation and reached a peak level after day 5. However, GzmF mRNA contents reached its peak level at day 8 . These observations were consistent with those of a previous study. ${ }^{18}$ To investigate whether GzmF has a role in cytotoxic lymphocyte-mediated cytolysis, GzmF was knocked down in LAK cells using short hairpin RNA (shRNA)-expressing adenovirus (Ad-shGzmF). In LAK cells, the GzmF mRNA level was reduced by $60 \%$ after Ad-shGzmF treatment. In contrast, the mRNA level of GzmB was not obviously altered (Figure $2 \mathrm{~b}$ left panel). GFP-expressing adenovirus (Ad-GFP) was used to infect LAK cells as a negative control.

We found that GzmF silencing did not show a significant decline of cytotoxicity compared with Ad-GFP control LAK cells (data not shown). This suggests the fact that other Gzms may provide fail-safe mechanisms to induce cytolysis of target cells. Our above data confirmed the fact that GzmF induces caspase-independent cell death. To exclude caspase-dependent death induced by GzmB and other caspase-dependent Gzms, Yac-1 cells were preincubated with a caspase pan inhibitor z-VAD, which blocked a caspase-dependent death pathway. We found that GzmF-silenced LAK cells decreased their cytotoxicity against z-VAD-treated Yac-1 cells compared with Ad-GFP control LAK cells (Figure $2 b$ right panel). These results suggest that GzmF has a role in caspase-independent cytolysis induced by LAK cells.

GzmF causes nuclear morphological changes. Chromatin condensation is considered to be a criterion for distinguishing apoptosis from necrosis. ${ }^{23}$ To determine the nature of GzmFinduced cell death, we visualized the nuclear morphological alterations of target cells by transmission electron microscopy. GzmF caused nuclear membrane collapse and chromatin condensation (Figure 3a). Chromatin was incompletely condensed and segmented at the nuclear periphery, which is distinct from that of GzmB or GzmC. In contrast, GzmB initiated a more compact nuclear condensation to form crescent or spherical shapes (Figure 3a). GzmC caused a condensed and shrunk nucleus. Mock-treated cells were uniform and did not change their nuclear morphology. These observations verify the fact that GzmF triggers a unique death program. Moreover, GzmF-treated cells exhibited obvious alterations in the cytosol. Cellular organelles were damaged by GzmF treatment (Figure 3a). The cytoplasm showed extensive vacuolization. However, GzmB-treated cells did not trigger obvious changes in the cytosol. Taken together, GzmF-induced death features are reminiscent of necroptosis. 
a Enterokinase

MDDDDK


C
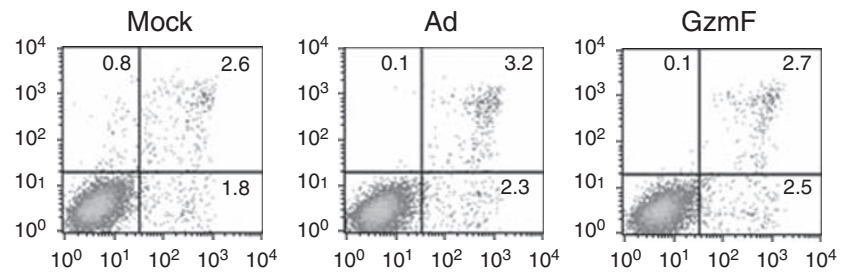

S-AGzmF/Ad


GzmF/Ad
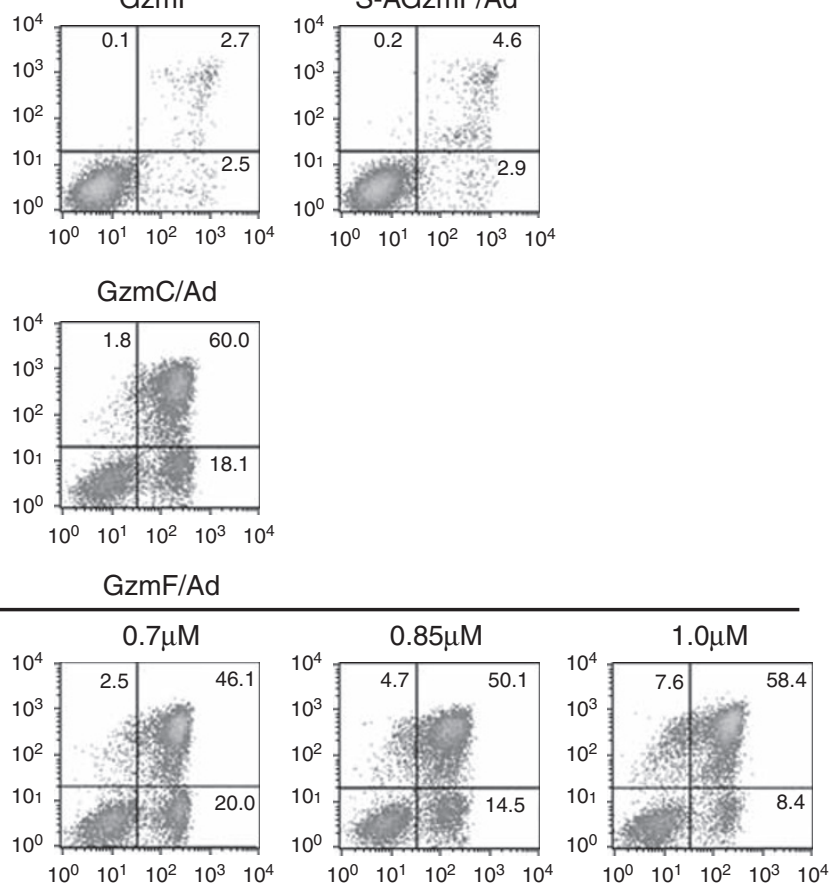

Annexin V 
GzmF causes single-stranded DNA nicks. For typical apoptosis, genomic DNA is degraded to $180-200 \mathrm{bp}$ oligonucleosomal fragments. To assess whether GzmF induces DNA fragmentation, we extracted genomic DNA from GzmF-treated cells and visualized it using an agrose gel. As shown in Figure 3b, GzmF failed to cause DNA laddering. GzmB was used as a positive control. We further checked whether ICAD is cleaved by GzmF. We found that GzmF did not degrade ICAD (data not shown). We next detected DNA nicking as previously reported. ${ }^{9}$ Nicked DNA can be labeled with ${ }^{32} \mathrm{P}-\mathrm{dATP}$ by a DNA polymerase I Klenow fragment and visualized with a denaturing alkaline agrose gel. GzmF caused single-stranded DNA nicking (Figure 3c). S-AGzmF/Ad or mock-treated target cells failed to make ${ }^{32} \mathrm{P}-\mathrm{dATP}$ incorporation. We previously identified $\mathrm{NM} 23 \mathrm{H} 1$ as a DNA nickase to nick DNA after GzmA treatment. ${ }^{24} \mathrm{NM} 23 \mathrm{H} 1$ binds its inhibitor SET to form a complex for blocking the DNase activity of $\mathrm{NM} 23 \mathrm{H} 1$. We demonstrated that GzmF did not degrade SET (Figure 3d). SET was not cleaved by GzmB, which was used as a
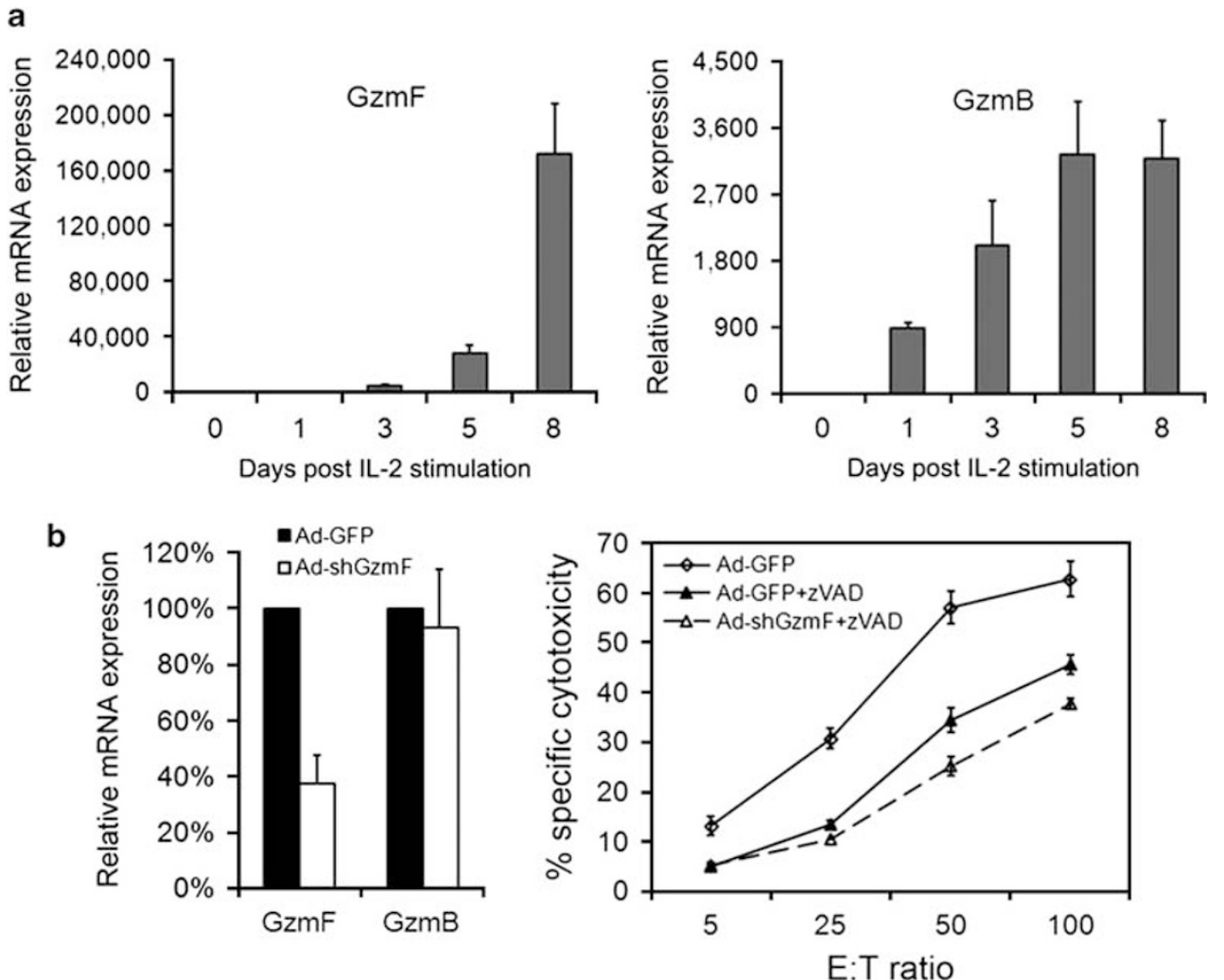

Figure 2 GzmF-silenced LAK cells reduce their cytotoxicity against caspase-inhibited target tumor cells. (a) GzmF mRNA expression is significantly upregulated in LAK cells. IL-2-stimulated LAK cells were harvested and their mRNA levels were determined by quantitative RT-PCR. Gzm mRNA levels were normalized to that of $18 \mathrm{~S}$ rRNA detected in the same sample. Data shown are representative of three separate experiments as means \pm S.D. (b) GzmF-silenced LAK cells reduce their cytotoxicity against caspase-inhibited target tumor cells. The GzmF expression was decreased to one-third through Ad-shGzmF treatment (left panel). Ad-GFP-infected LAK cells were used as a negative control. GzmB expression was not obviously changed after Ad-shGzmF treatment. Cytotoxicity against the Yac-1 target cell was assessed as described in Materials and Methods section. Ad-shGzmF-treated LAK cells showed a reduced cytotoxicity against z-VAD-FMK (100 $\mu \mathrm{M})$-pretreated Yac-1 cells compared with Ad-GFP control LAK cells (right panel). These data are representative of three experiments as shown with means \pm S.D.

Figure 1 GzmF induces target cell death. (a) Production of recombinant GzmF and enzymatic assay. Recombinant GzmF and point-mutated S-AGzmF were expressed and refolded in inclusion bodies and activated by enterokinase treatment. Samples were separated by $12 \%$ SDS-PAGE and visualized by Coomassie brilliant blue staining (left panel). proGzmF, GzmF with enterokinase cleavage sequence. Recombinant GzmF ( $50 \mathrm{nM}$ ) showed enzymatic activity toward the synthetic substrate (left panel). Suc-PheLeu-Phe-pNA (FLF-pNA). GzmF had no activity toward PTSY-pNA (substrate of GzmH), AAF-pNA (substrate of tripeptidyl peptidase I and II), AAPF-pNA (substrate of cathepsin G) and AAPL-pNA (substrate of GzmM). These data are representative of three independent experiments. (b) Yac-1 cells were preincubated with $\mathrm{Na}_{2}{ }^{51} \mathrm{CrO}_{4}$ at $37^{\circ} \mathrm{C}$ for $1 \mathrm{~h} .{ }^{51} \mathrm{Cr}$-labeled cells were treated with $0.5 \mu \mathrm{M}$ GzmF, S-AGzmF, GzmC and GzmB plus Ad at $37^{\circ} \mathrm{C}$ for $6 \mathrm{~h}$. Released ${ }^{51} \mathrm{Cr}$ was counted by Microbeta counter (PerkinElmer) and presented as means \pm S.D. Cells were mock-treated or treated with $\mathrm{Ad}$ and $0.5 \mu \mathrm{M} \mathrm{GzmF}$ alone as negative controls. These data represent three separate experiments. (c) GzmF causes phosphatidylserine externalization. Yac-1 cells $\left(2 \times 10^{5}\right)$ were incubated with Ad, $1 \mu \mathrm{M}$ GzmF alone, $1 \mu \mathrm{M}$ S-AGzmF plus Ad, $1 \mu \mathrm{M}$ GzmB or $\mathrm{GzmC}$ plus Ad and with increased concentrations of GzmF plus Ad at $37^{\circ} \mathrm{C}$ for $6 \mathrm{~h}$. Cells were stained with FITC-conjugated Annexin V (AV) and PI for flow cytometry assay. These data are representative of four separate experiments. Staurosporine (STP) was used as a positive control. (d) Percentages of AV single-positive versus AV/PI doublepositive cells. The black bar and the gray bar represent AV single-positive and AV/PI double-positive cells, respectively. These data were calculated from three experiments shown as means \pm S.D. 

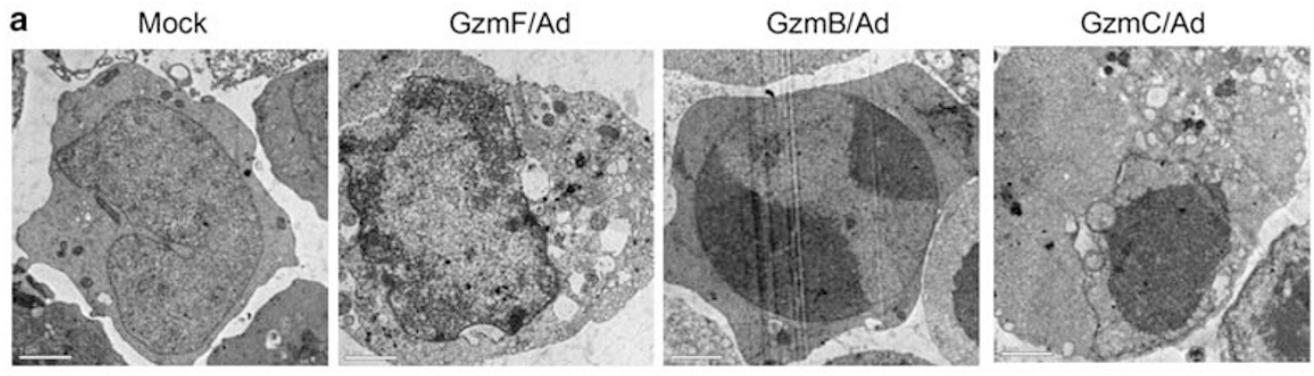

b

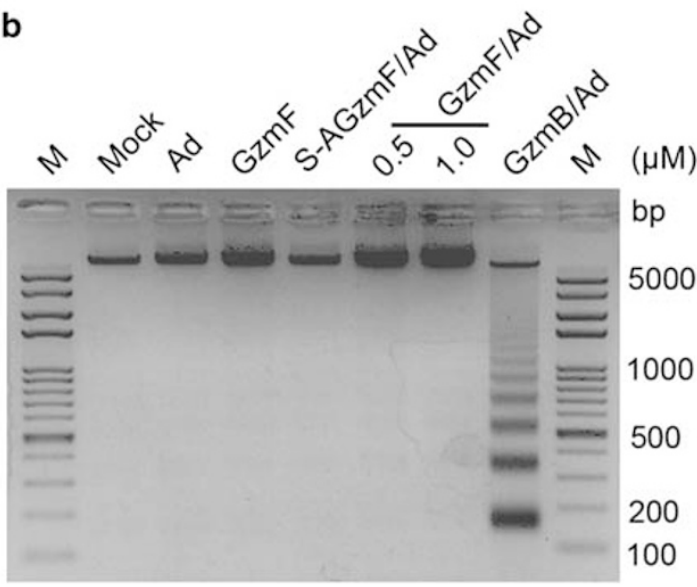

c

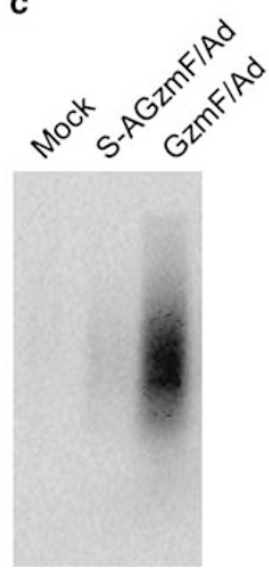

d

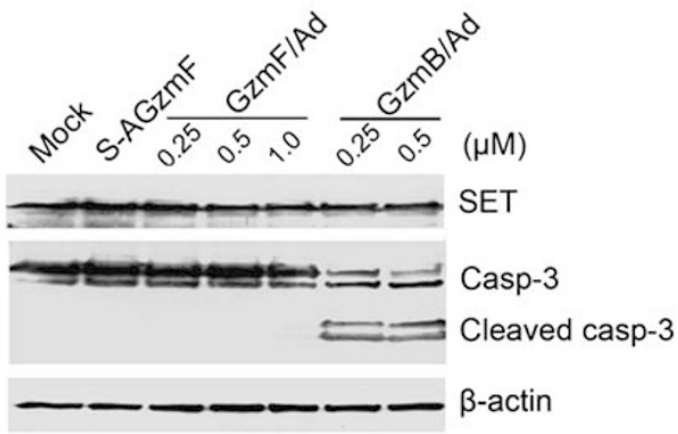

Figure 3 GzmF causes nuclear morphological changes with single-stranded DNA nicking. (a) Nuclear morphological changes induced by GzmF. Yac-1 cells were treated by $0.5 \mu \mathrm{M} \mathrm{GzmF}, \mathrm{GzmB}$ or GzmC in the presence of $\mathrm{Ad}$ at $37^{\circ} \mathrm{C}$ for $6 \mathrm{~h}$. Cells were harvested and visualized by transmission electron microscopy (magnification $\times 1700$ ). GzmB/Ad and GzmC/Ad were used as contrast. (b) GzmF does not cause DNA laddering. Yac-1 cells were treated with S-AGzmF (1 $\mu \mathrm{M})$ and with the indicated concentrations of GzmF plus Ad at $37^{\circ} \mathrm{C}$ for $6 \mathrm{~h}$. Genomic DNA was extracted and separated on $2 \%$ agarose gel stained with ethidium bromide. M, DNA marker. (c) GzmF induces single-stranded DNA nicks. GzmF/Ad-treated Yac-1 cells were radiolabeled with ${ }^{32} \mathrm{P}$-dATP by Klenow fragment. Genomic DNA was then harvested and visualized by denaturing alkaline gel electrophoresis. These data are representative of at least three independent experiments. (d) GzmF does not cleave SET. Yac-1 cells $\left(3 \times 10^{5}\right)$ were treated with different concentrations of GzmF or GzmB plus Ad. Samples were harvested and detected with anti-SET antibody. Caspase-3 (casp-3) was probed as a positive control for GzmB. $\beta$-Actin was used as a loading control

negative control. Caspase- 3 activation induced by GzmB was used as a positive control. $\beta$-Actin was unchanged as a loading control. This suggests that DNase $\mathrm{NM} 23 \mathrm{H} 1$ is not activated in GzmF-induced death.

GzmF initiates mitochondrial swelling, depolarization and ROS generation. Mitochondrial damage is an initial step in the induction of apoptosis. We visualized mitochondrial alterations in GzmF-induced cell death by transmission electron microscopy. GzmF plus Ad treatment caused dilating and swelling of the mitochondria, followed by a loss of the cristae structure and a rupture of membrane (Figure 4a). Mock-treated cells showed a normal state of mitochondria with an elliptical shape and narrow cristae. GzmB caused mitochondrial damage as a positive control.

The above observations indicate that normal mitochondrial functions may be destroyed by GzmF. We used a sensitive dye, $\mathrm{DiOC}_{6}(3)$, to monitor the loss of membrane potential $\left(\Delta \psi_{\mathrm{m}}\right)$ with $\mathrm{GzmF}$ treatment. We found that GzmF initiated a dose-dependent loss of $\Delta \psi_{\mathrm{m}}$ (Figure $4 \mathrm{~b}$ ). At a concentration of $1 \mu \mathrm{M}, \mathrm{GzmF}$ resulted in a nearly complete loss of $\Delta \psi_{\mathrm{m}}$. Mocktreated, Ad or S-AGzmF/Ad-treated cells showed background changes of $\Delta \psi_{\mathrm{m}}$. GzmB/Ad-treated cells were used as a positive control. Reactive oxygen species (ROS) have been considered as critical regulators in the induction of apoptosis. Mitochondria are the main source of intracellular ROS. ROS can be produced after a damage to the mitochondrial inner membrane. To assess ROS production in GzmF-treated cells, Yac-1 cells were probed with an oxidation-sensitive dye, $\mathrm{H}_{2}$ DCF-DA, which shows a basal level of fluorescence at a reduced state and is converted into strong fluorescence after oxidation by intracellular ROS. GzmF led to ROS accumulation in a dose-dependent manner (Figure 4c). Mock-treated, Ad or S-AGzmF/Ad-treated cells failed to generate ROS. GzmB/Ad-treated cells were able to produce ROS. $\mathrm{H}_{2} \mathrm{O}_{2}$-treated cells were utilized as a positive control. These above data are representative of at least four separate experiments.

GzmF triggers cyt $c$ release from mitochondria to cytosol. Cyt $c$ release from mitochondria to cytosol is a key event during apoptosis. To investigate cyt $c$ release in GzmF-induced cell death, we fractionated mitochondrial and cytosolic sections after GzmF/Ad treatment, followed by probing of cyt $c$ by western blotting. GzmF caused cyt $c$ release in a dose-dependent manner (Figure 5a left panel). 
a

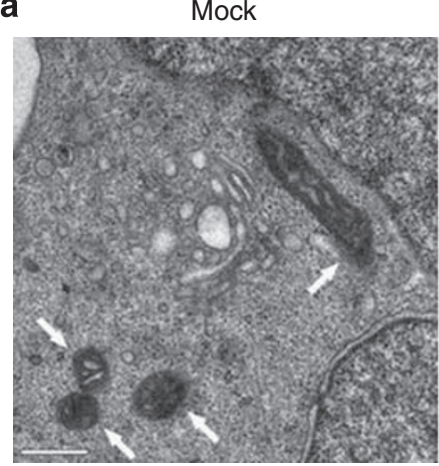

GzmF/Ad

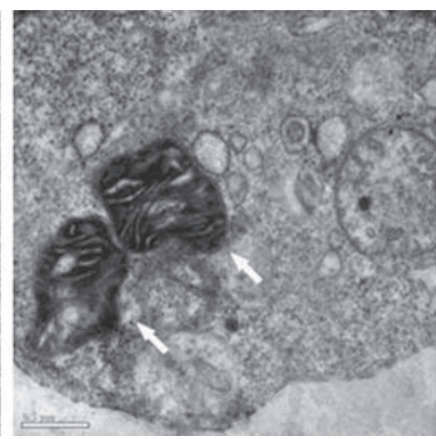

GzmB/Ad



b

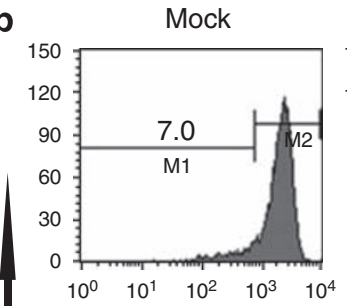

$\mathrm{Ad}$

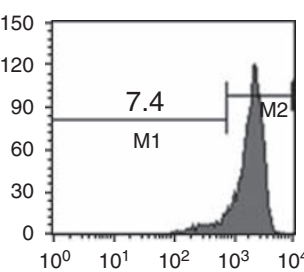

S-AGzmF/Ad

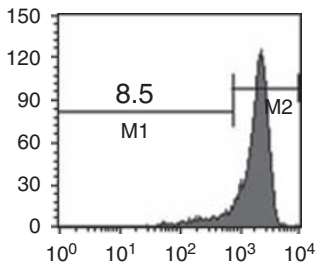

GzmB/Ad

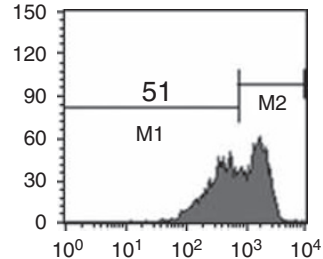

GzmF/Ad
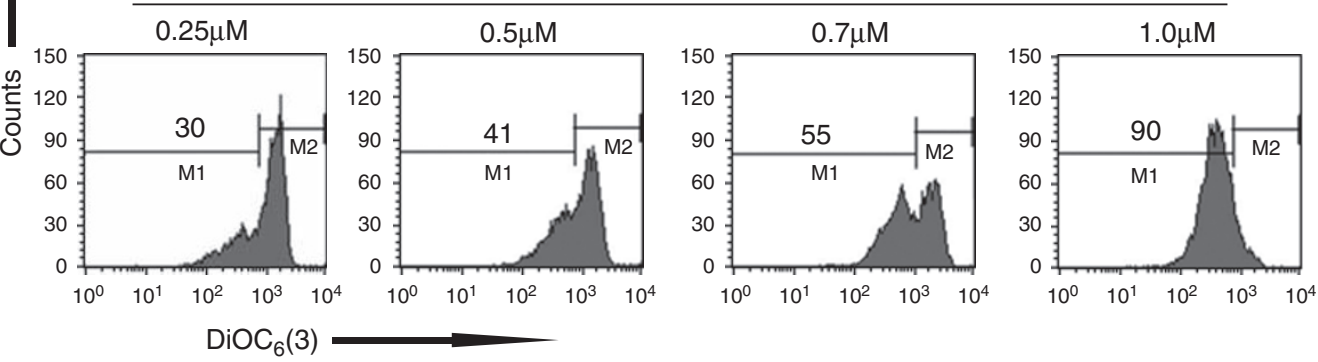

C
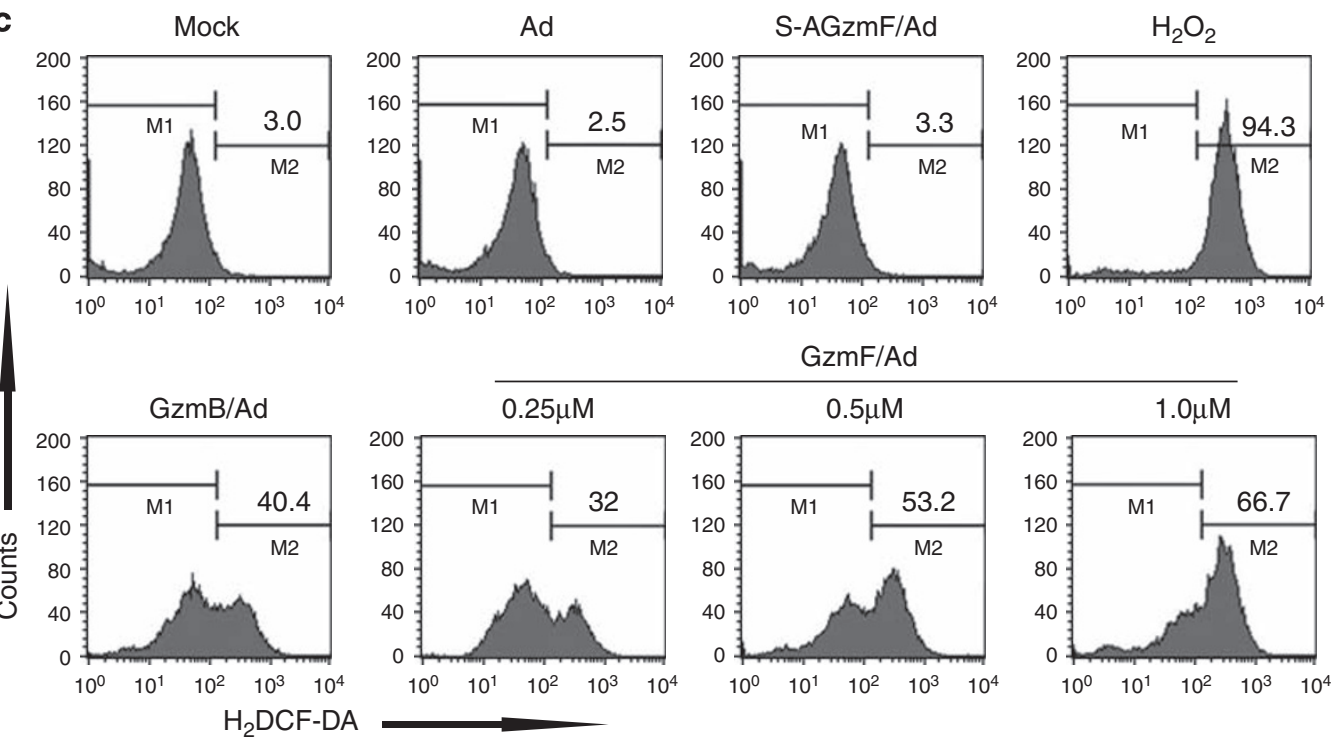

Figure 4 GzmF targets mitochondria of target cells. (a) Mitochondrial damage was detected by transmission electron microscopy (magnification $\times 6500$ ). Mitochondria were indicated with white arrows. Yac-1 cells were incubated with $0.5 \mu \mathrm{M} \mathrm{GzmF}$ or GzmB in the presence of $\mathrm{Ad}$ at $37^{\circ} \mathrm{C}$ for $6 \mathrm{~h}$. (b) GzmF induces loss of mitochondrial membrane potential $\left(\Delta \psi_{\mathrm{m}}\right)$. Yac-1 cells were treated with the increased doses of GzmF or GzmB in the presence of Ad at $37^{\circ} \mathrm{C}$ for $6 \mathrm{~h}$. Treated cells were stained with $\mathrm{DiOC}_{6}(3)$ and analyzed by flow cytometry. (c) ROS generation in GzmF-treated cells. Yac-1 cells were preincubated with $\mathrm{H}_{2} \mathrm{DCF}-\mathrm{DA}$ at $37^{\circ} \mathrm{C}$ for $30 \mathrm{~min}$. Different doses of $\mathrm{GzmF}$ were then loaded in the presence of $\mathrm{Ad}$ for $2 \mathrm{~h}$ and analyzed by flow cytometry. $\mathrm{GzmB}$ and $\mathrm{H}_{2} \mathrm{O}_{2}$ were used as positive controls. These data are representative of three independent experiments 

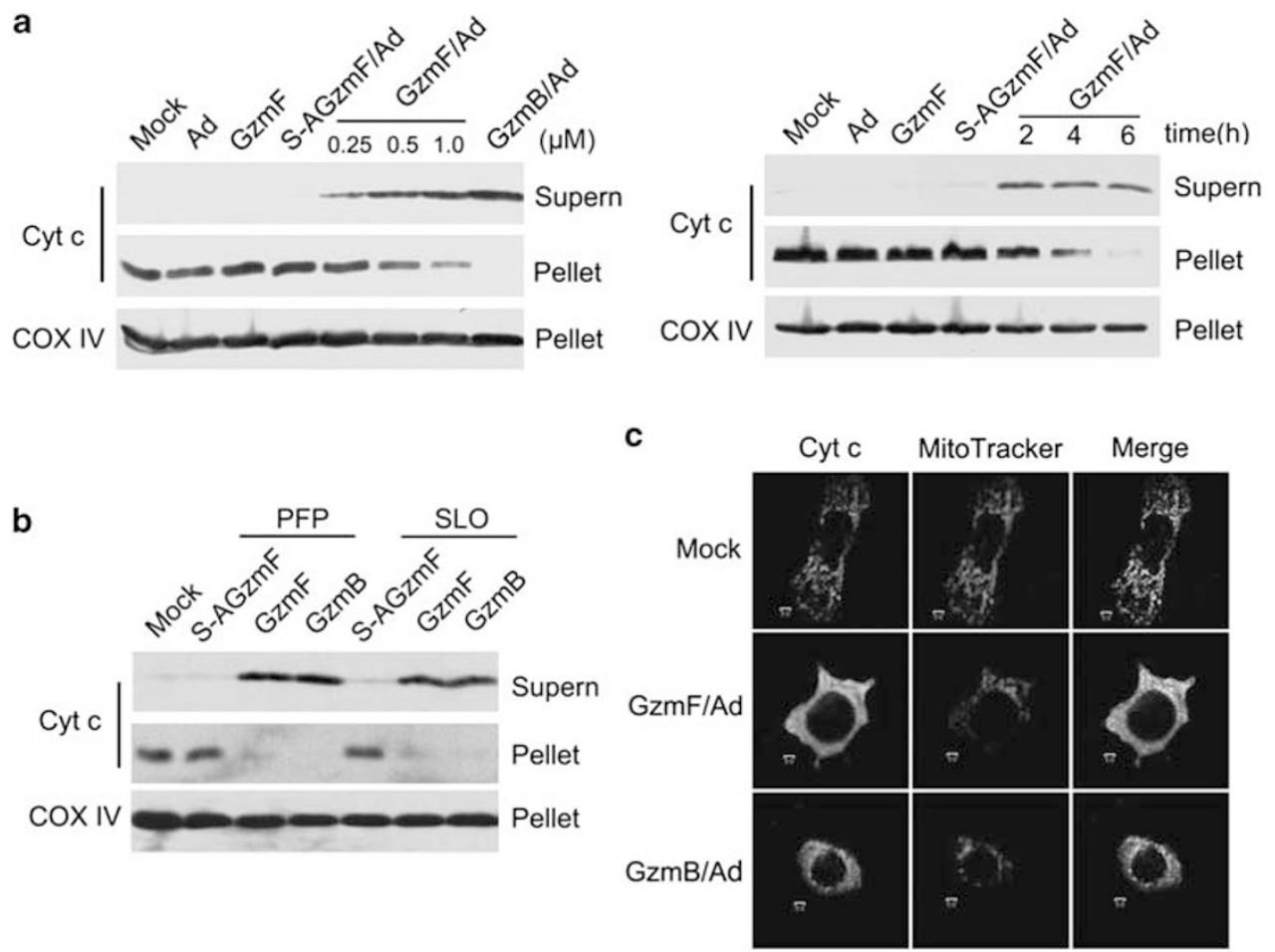

Figure $5 \mathrm{GzmF}$ initiates cytochrome $c$ release. (a) GzmF causes cyt $c$ release in a dose- and time-dependent manner. Yac- 1 cells $\left(3 \times 10^{5}\right)$ were treated with indicated concentrations of GzmF (left panel) and with the increased times of GzmF $(0.5 \mu \mathrm{M})$ (right panel) plus Ad. The same pellet blot was stripped and reprobed with anti-COX IV antibody as a loading control. These data are representative of at least three independent experiments. supern, supernatant. (b) Yac-1 cells were treated with $0.5 \mu \mathrm{M} G z m F$ plus sublytic PFP or SLO. Cyt $c$ was probed as above. (c) Cyt $c$ release was confirmed by confocal microscopy. MEFs were treated with $\mathrm{GzmF}$ or GzmB plus Ad at $37^{\circ} \mathrm{C}$ for $2 \mathrm{~h}$. Cells were fixed, permeabilized and stained for cyt $c$. Cyt $c$ staining green fluorescence is shown on the left, Mitotracker with red fluorescence is shown in the middle and the merged image at the right

To further define the time course of the release of cyt $c$, $0.5 \mu \mathrm{M}$ GzmF was loaded with Ad into Yac-1 cells at different times. We found that cyt $c$ release occurred within $2 \mathrm{~h}$ and reached a roughly maximal release at that time (Figure $5 \mathrm{a}$ right panel), although COX IV, a mitochondria matrix protein, remained unchanged in the treated mitochondrial pellets. Mock-treated, Ad and GzmF alone, or S-AGzmF/Ad-treated cells did not cause cyt $c$ release. GzmB/Ad-treated cells were used as a positive control. We utilized an optimal dose of PFP or streptolysin O (SLO) for delivering Gzms into Yac-1 cells, and similar results were obtained (Figure $5 b$ ). GzmB was used as a positive control. These observations were confirmed by confocal microscopy (Figure $5 \mathrm{c}$ ).

Cyt $c$ release is independent of Bid, Bax and Bak. To examine whether Bid participates in GzmF-induced cyt $c$ release, mitochondrial and cytosolic fractions were probed with an anti-Bid antibody. Bid remained unchangeable in cytosolic fractions after different doses of GzmF treatment with Ad (Figure 6a). Bid was undetectable in cytosol and tBid appeared in the pellet after GzmB treatment (Figure 6a). These data indicate that Bid was completely cleaved to tBid and the processed tBid translocated into mitochondria in GzmB-loaded cells. Our observations are consistent with previous reports. ${ }^{25,26}$ We further showed that Bid was not processed to tBid in GzmF-loaded cells, whereas
Bid was activated to tBid by GzmB treatment (Figure 6b). Caspase-3 was probed as a positive control for GzmB. $\beta$ Actin was used as a loading control.

To further verify whether Bid is required for GzmF-caused cyt $c$ release, Bid WT and knockout mouse embryonic fibroblast (MEFs) were treated by GzmF/Ad to assess cyt $c$ release. Cyt $c$ was still released in Bid-deficient MEFs, a process similar to that of WT MEFs (Figure 6c). Mock-treated, or S-AGzmF/Ad-treated cells did not release cyt $c$. COX IV was used as a good loading control. Cyt $c$ release still needs the enzymatic activity of GzmF, although GzmB did not induce cyt $c$ release in Bid-deficient MEFs. Bax and/or Bak induce a selective process of outer membrane permeabilization of mitochondria through the formation of channels or pores that allow the selective protein release soluble in the inner membrane space such as cyt $c$. We then detected whether cyt $c$ is released from GzmF-treated Bax/Bak doubleknockout (DKO) MEFs. We found that both Bax/Bak WT and DKO MEFs induced cyt $c$ release from mitochondria (Figure 6d). However, GzmB did not induce cyt $c$ release in Bax/Bak-deficient MEFs. COX IV was used as a good loading control. We further assessed active Bax with a specific Bax antibody in GzmF-loaded cells through confocal microscopy. Activated Bax was validated in GzmB/Ad-loaded cells and not in GzmF/Ad-loaded cells (Figure 6e). Therefore, our findings indicate that GzmF-induced cyt $c$ release is independent of Bid or Bax/Bak. 
a

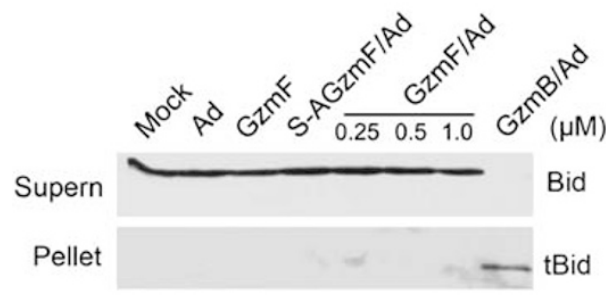

b

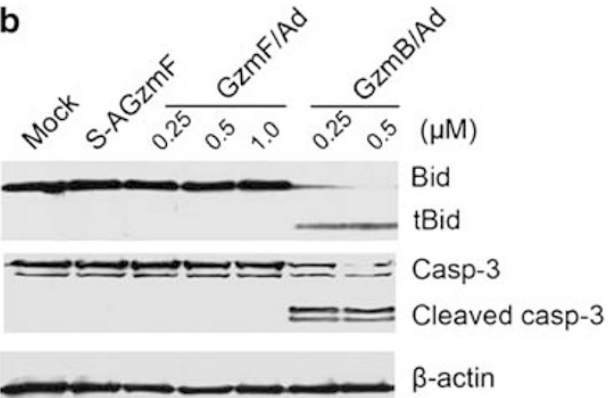

C


d



Figure 6 Cytochrome $c$ release is independent of Bid or Bax/Bak. (a) GzmF-induced cyt $c$ release is independent of Bid. The same immunoblots from the left panel of Figure 5 a were stripped and reprobed with anti-Bid antibody. Full-length Bid detected in supernatants remained unchanged after GzmF treatment. GzmB processed Bid to tBid and tBid translocated to mitochondria. The loading control of COX IV blotting was shown in Figure 5 a left panel. (b) GzmF does not process Bid to tBid. Yac- 1 cells $\left(3 \times 10^{5}\right)$ were treated with different doses of GzmF or GzmB plus Ad at $37^{\circ} \mathrm{C}$ for $2 \mathrm{~h}$. Bid was detected by western blotting. Caspase-3 was probed as a positive control for GzmB. $\beta$-Actin was used as a loading control. (c) GzmF causes cyt $c$ release in Bid-deficient MEFs. WT and Bid ${ }^{-1-} \mathrm{MEFs}\left(3 \times 10^{5}\right)$ were loaded with $0.5 \mu \mathrm{M} \mathrm{S-AGzmF} \mathrm{or} \mathrm{with} \mathrm{GzmF}$ plus $\mathrm{Ad}$ at $37^{\circ} \mathrm{C}$ for $4 \mathrm{~h}$. Cytoplasmic or pellet fractions were separated and probed for cyt $\mathrm{c}$. GzmB and COX IV were used as positive or loading controls, respectively. (d) Cyt $\mathrm{c}$ release is independent of Bax/Bak. Bax/BakWT or DKO MEFs $\left(3 \times 10^{5}\right)$ were treated as above for cyt $c$ detection. GzmB was used as a positive control. COX IV was used as a loading control. (e) Bax cannot be activated in GzmF-treated cells. MEFs were mock treated (left), or treated with $0.5 \mu \mathrm{M} \mathrm{GzmF} \mathrm{(middle)} \mathrm{or} \mathrm{GzmB} \mathrm{(right)} \mathrm{plus} \mathrm{Ad} \mathrm{at} 37^{\circ} \mathrm{C}$ for $4 \mathrm{~h}$. Activated Bax was probed by immunofluorescent staining. These data represent at least three separate experiments. Activated Bax with FITC staining is shown in the upper panel, differential interference contrast (DIC) in the middle panel, and the merged image in the bottom panel. Supern, supernatant; casp-3, caspase-3 



Figure 7 GzmF cannot trigger caspase activation. (a) GzmF-induced death can-not be inhibited by caspase-pan inhibitor Z-VAD-FMK in the presence of Ad (left panel) or PFP/SLO (right panel). Yac-1 cells were pretreated with $100 \mu \mathrm{M}$ Z-VAD-FMK before GzmF treatment. Z-VAD-FMK can block GzmB-induced apoptosis that was used as a positive control. Total dead cells were calculated by $\mathrm{AV}^{+}$plus $\mathrm{AV}^{+} / \mathrm{PI}^{+}$cells and are shown as means \pm S.D. *, $P<0.05 ; * *, P<0.01$. (b) GzmF does not initiate the caspase activation cascade. Yac-1 cells $\left(4 \times 10^{5}\right)$ were treated with $0.5 \mu \mathrm{M} \mathrm{GzmF}$ and GzmB at the indicated times. Caspase activity was measured in cellular lysates. GzmB/Ad-treated cells were used as a positive control. Data were shown as means \pm S.D. (c) Caspase inactivation was confirmed by western blotting. Cells $\left(2 \times 10^{5}\right)$ were loaded with GzmF or GzmB as above and caspases 2, 3, 8 and 9 were probed with each specific antibody. Gzms were delivered with Ad (left panel) or sublytic concentrations of PFP or SLO (right panel). Cell death was verified by trypan blue staining 
GzmF-induced cell death is caspase independent. Once cyt $c$ releases into the cytosol, it can bind cytosolic apoptotic protease-activating factor 1 (Apaf-1) and procaspase-9 to form an apoptosome in the presence of ATP, which causes the caspase activation cascade to execute apoptosis. ${ }^{27}$ As mentioned above, GzmF can cause cyt $c$ release at an early

a



b

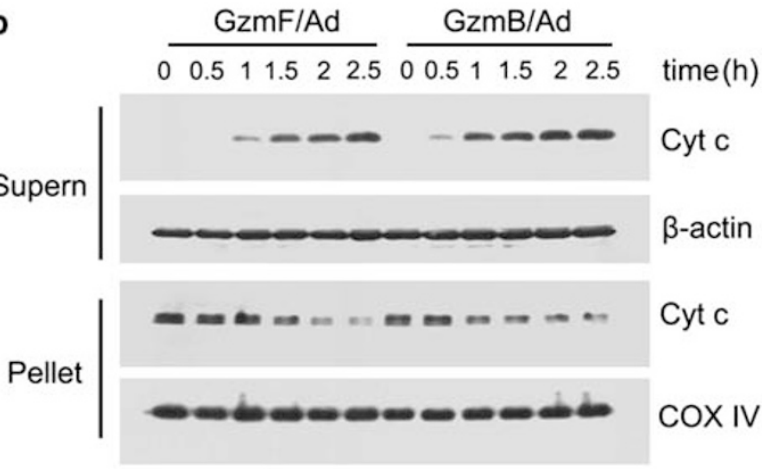

C

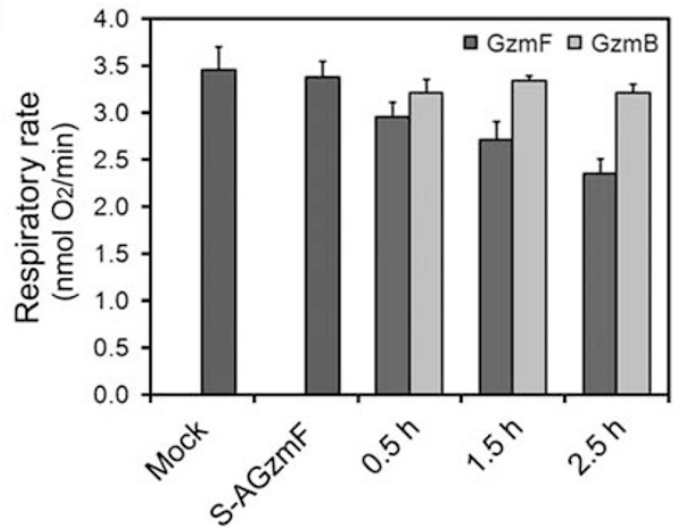

Figure 8 GzmF disrupts mitochondrial electron transport leading to the loss of ATP. (a) Cellular ATP dramatically declines after GzmF treatment. Yac-1 cells $\left(4 \times 10^{5}\right)$ were treated with $0.5 \mu \mathrm{M} \mathrm{GzmF}$ or GzmB plus Ad at $37^{\circ} \mathrm{C}$ for the increased times. Intracellular ATP levels were assessed as described in the methods. ATP contents were calculated as means \pm S.D. Data are representative of at least four separate experiments. (b) Dynamic cyt $c$ release with GzmF treatment. The other halves of the treated cells in panel a were probed for cyt $c$ by western blotting. $\beta$-Actin and COX IV were used to control protein loading. (c) GzmF abolishes the mitochondrial respiration of target cells. Yac-1 cells $\left(3 \times 10^{6}\right)$ were treated with $0.5 \mu \mathrm{M} \mathrm{GzmF}$ or $\mathrm{GzmB}$ plus Ad at $37^{\circ} \mathrm{C}$ for the indicated times. Oxygen consumption rates were calculated and designated as $\mathrm{nmol}_{2} / \mathrm{min}$ (means \pm S.D.). These data represent at least three separate experiments stage of cell death program, hence we presumed that caspase activation has to occur to execute cell death after GzmF treatment. Surprisingly, the caspase pan-inhibitor Z-VAD-FMK did not significantly inhibit GzmF-induced cell death $(52.6 \pm 3.6$ versus $45.2 \pm 4.2 \%, P>0.05)$ (Figure $7 a$ left panel). Z-VAD-FMK can block GzmB-caused death $(56.2 \pm 1.8$ versus $16.1 \pm 0.2 \%, P<0.01)$. These observations were confirmed by loading Yac-1 cells with PFP or SLO (Figure 7a right panel). Moreover, we pretreated cells with different caspase inhibitors, including caspase-2 inhibitor Z-VDVAD-FMK, caspase-3 inhibitor Z-DEVD-FMK, caspase-8 inhibitor Z-IETD-FMK or caspase-9 inhibitor Z-LEHD-FMK before GzmF loading. All inhibitors cannot suppress GzmF-induced death (data not shown).

We also measured the activities of caspases in GzmFloaded cells with specific fluorogenic substrates Ac-DEVDAFC (caspase-3 and 7), Z-VDVAD-AFC (caspase-2), Z-IETD-AFC (caspase-8) and Ac-LEHD-AFC (caspase-9). GzmF treatment did not activate all the detected caspases (Figure 7b). Cell death was confirmed by trypan blue staining. GzmB activates caspases very early and reaches a peak level within $4 \mathrm{~h}$. We also verified these observations in GzmFloaded Yac-1 cells in the presence of Ad, PFP or SLO by western blotting (Figure 7c). All these procaspase forms remained unchangeable after GzmF treatment. GzmB could process all procaspase forms to active caspases. $\beta$-Actin was probed as a loading control. Taken together, GzmF-induced death did not depend on caspase activation.

GzmF impairs mitochondrial electron transport to disrupt ATP generation. Although cyt $c$ was released from the mitochondria into cytosol, caspase activation did not exist in GzmF-treated target cells. Cytosolic cyt $c$ recruits Apaf-1 and procaspase-9 in an ATP-dependent manner to assemble an apoptosome, leading to caspase activation. We first detected the contents of procaspase-9 after GzmF treatment. Procaspase-9 maintained similar levels in GzmFtreated and mock-treated cells (data not shown). Considering the fact that ATP is essential for the formation of apoptosome, we measured the ATP contents of Gzmstreated Yac-1 cells. After GzmF treatment, cellular ATP concentrations diminished dramatically at an early time point, which dropped to half within $2.5 \mathrm{~h}$ (Figure 8a). The ATP decrease was in agreement with dynamic cyt $c$ release after GzmF treatment (Figure 8b). One-fourth of ATP contents were consumed within $1 \mathrm{~h}$ of treatment, whereas at this time point, cyt $c$ release was just slightly detectable in the cytosolic fraction. In contrast, GzmB treatment induced a short-term elevation of ATP levels at early stages, which dropped slightly even within $2.5 \mathrm{~h}$ (Figure 8a). ATP levels rose continuously to reach a maximal value within $0.5-1 \mathrm{~h}$ and then gradually decreased. At this period, GzmB induced a high level of cyt $c$ release (Figure $8 b$ ). GzmB caused cyt $c$ release with the elevation of ATP at an early stage. These observations imply that apoptosomes could be formed in GzmB-treated cells. GzmF-induced cell death caused a dramatic decline in ATP contents. ATP decline may favor the formation of inactive Apaf-1 aggregates and may prevent apoptosome assembly. ${ }^{28} \beta$-Actin and COX IV remained 
unchanged and served as loading controls. These data are representative of at least three independent experiments.

ATP is the main energy storage in cells and is mostly generated by mitochondrial electron transport chains. We detected oxygen consumption of target cells after GzmF treatment. We found that cells reduced mitochondrial respiratory rates in a time-dependent manner after GzmF treatment (Figure 8c), whereas GzmB caused little change during the treated time. Therefore, the disruption of mitochondrial respiration might partially contribute to loss of ATP.

\section{Discussion}

In this study, we found that murine GzmF can induce a novel cell death program. Our data demonstrated that induction of cell death needs its enzymatic activity and is characterized by PS externalization, nuclear condensation, mitochondrial damage, cyt $c$ release and single-stranded DNA nicking. However, GzmF-induced cell death takes place without caspase activation, although cyt $c$ is released. Moreover, cyt $c$ release is independent of Bid or Bax/Bak. We knocked down the expression of GzmF in LAK cells and observed a reduced cytotoxicity against caspase-inhibited target tumor cells. We further showed that GzmF impairs mitochondrial electron transport to abolish ATP generation. The loss of ATP may contribute to a failure of apoptosome assembly, leading to caspase inactivation.

Granzyme F-induced cell death takes place rapidly. Unlike typical apoptosis, GzmF-induced death has many unique features. AV and PI double-positive cells are predominant in GzmF-induced death. It indicates that membrane integrity is disrupted during the induction of death. Nuclear morphology showed a less compact or an incomplete chromatin condensation that is partially segmented at the nuclear periphery. These features are in agreement with necroptosis, which is a necrotic form of programed cell death. ${ }^{29,30}$ For necroptosis, the nuclear morphological changes are not with obvious chromatin condensation, but with chromatin clustering to speckles. We compared nuclear morphological changes and other death features among three death types of apoptosis, necrosis and necroptosis in another of our just published paper. $^{31}$

The DNA damage is characterized by single-stranded DNA nicking. Indeed, GzmF cannot cleave ICAD, the inhibitor of caspase-activated DNase, leading to DNA fragmentation (data not shown). We previously identified $\mathrm{NM} 23 \mathrm{H} 1$ as a DNA nickase. ${ }^{24}$ It binds its inhibitor SET to form a complex, which is predominantly cytoplasmic. The DNase activity of $\mathrm{NM} 23 \mathrm{H} 1$ was released through a degradation of its inhibitor SET after GzmA or GzmK treatment. ${ }^{9}$ However, GzmF does not degrade SET. It suggests that DNase $\mathrm{NM} 23 \mathrm{H} 1$ is not activated in GzmF-induced death. Nevertheless, several possible factors could account for this nuclear damage. Endonuclease G (Endo G) and AIF are considered to be involved in chromatin condensation triggered by several stimuli. $^{32,33}$ We found that both Endo $G$ and AIF were released from mitochondria to cytosol after GzmF treatment (data not shown). However, whether Endo G or AIF initiates DNA nicking remains to be further studied.
Mitochondria have a major role in both caspase-dependent and -independent death programs. They contain a number of proapoptotic proteins, such as cyt $c$, Endo G, AIF and SMAC, which are released into the cytosol in the induction of cell death. ${ }^{34}$ GzmF initiates mitochondrial damage and results in the release of cyt $c$. Cyt $c$ release is often triggered by proapoptotic Bcl-2 family members, including Bid, Bax and Bak. These proteins translocate from the cytosol to mitocondria after a death signal. Bid can be processed to tBid, which recruits Bax or Bak to mitochondria through a caspasedependent machinery, where it is integrated into the outer mitochondrial membrane to trigger the release of cyt $c$ and other proapototic factors. Cyt $c$ release induced by GzmB or GzmK is through the processing of Bid to tBid. ${ }^{22,25}$ However, GzmF cannot activate Bid to tBid in the induction of death. Cyt $c$ was still released in $\mathrm{Bid}^{-1-}$ and Bax/Bak DKO MEF cells with GzmF treatment but was not released with GzmB treatment. We further found GzmF alone could not mediate cyt $c$ release in isolated mitochondria (unpublished data). These observations suggest that some unknown cellular factors may be required for the release of cyt $c$ during GzmF-induced death.

Cyt $c$ release from the mitochondria to cytoplasm has been considered to be an important event in the activation of downstream caspases during apoptosis. Once cyt $c$ is released into cytosol, it binds Apaf-1, procaspase- 9 and ATP/dATP to form an apoptosome, which subsequently activates caspase-3 to execute the caspase activation cascade. Cytosolic ATP level has a critical role in forming an apoptosome or inactive aggregates during this process. In the absence of ATP, cyt $c$ binding to Apaf-1 triggers its inactive aggregation. ${ }^{28}$ Several reports showed that intracellular ATP levels remain unchanged or even elevated for a short time in STP or in etoposide-induced apoptosis, and then gradually decrease until the very end of the death process. ${ }^{35-37}$ We first demonstrated that this phenomenon occurs in GzmB-induced apoptosis (Figure 8a). However, we found that, after GzmF treatment, intracellular ATP diminishes at an early stage, which is much earlier than cyt $c$ release. Therefore, loss of intracellular ATP may fail to assemble apoptosomes, leading to caspase inactivation.

ATP is generated through the oxidative phosphorylation (OXPHOS) system in the mitochondrial inner membrane. The OXPHOS system consists of four respiratory chain complexes (complexes I to IV), which transfer electrons from the reducing equivalent (NADH-FADH2) to molecular oxygen, generating a proton gradient in the mitochondrial intermembrane space, and of the ATP synthase that uses this proton gradient to generate ATP. Complex I is a large multienzyme complex consisting of at least 46 subunits, which is the main source of ROS and the major route of entry of electrons into the respiratory chain. A recent report showed that the p75 subunit of respiratory complex $I$ is degraded as a caspase substrate during apoptosis. ${ }^{38}$ Cells expressing a noncleavable mutant p75 maintain $\Delta \psi_{\mathrm{m}}$ and ATP levels during apoptosis. GzmF-induced death takes place without caspase activation. Moreover, we found that the p75 subunit of complex I is not degraded after GzmF treatment, and GzmF cannot directly destroy the respiration complex I activity in isolated mitochondria (data not shown). Nevertheless, GzmFtreated target cells reduce mitochondrial respiratory rates in 
induction of cell death. These observations demonstrate that GzmF indeed destroys the electron transport of the OXPHOS system. The molecular mechanism of GzmF-mediated ATP decline remains to be further investigated.

\section{Materials and Methods}

Recombinant Gzms expression and purification. Murine GzmF was cloned from cDNA templates prepared from a mouse thymus. PCR was performed using the following primers: sense (5'-ATGCCACCAATCCTGATTCTC- $\left.3^{\prime}\right)$ and antisense (5'-CGGGTGGTTTAACTCCTGTTA- $\left.3^{\prime}\right)$. Active GzmF cDNA was subcloned into $\mathrm{pET} 26 \mathrm{~b}$ with an enterokinase cleavage site before $\mathrm{N}$-terminal amino acids IIGG. Inactive counterpart S-AGzmF was generated by point mutation. Both proteins were expressed and refolded from Rosetta (DE3) (Novagen, Darmstadt, Germany) inclusion bodies as described. ${ }^{19}$ After thoroughly washing and refolding for 3 days, proteins were harvested and activated by enterokinase treatment. The enterokinase was removed and GzmF was purified on a Hitrap ion exchange column (Amersham Biosciences, Pittsburgh, PA, USA). Recombinant human GzmB and murine GzmC were expressed in the same way.

Enzymatic activity of recombinant GzmF. Granzyme F was incubated with synthetic peptide substrates in a buffer $(50 \mathrm{mM}$ Tris- $\mathrm{HCl}, \mathrm{pH} 8.0,150 \mathrm{mM} \mathrm{NaCl})$ at RT for $30 \mathrm{~min}$. Suc-Phe-Leu-Phe-pNA and Suc-Ala-Ala-Pro-Leu-pNA were purchased from Bachem (Bubendorf, Switzerland). Suc-Ala-Ala-Pro-Phe-pNA, HAla-Ala-Phe-pNA, Z-Phe-Arg-AMC and Z-Arg-Arg-AMC were from Sigma-Aldrich (St Louis, MO, USA). Suc-Phe-Thr-Ser-Tyr-pNA was synthesized by Chinese Peptide Company (Hangzhou, China). ODvalues were measured using a Wallac VICTOR reader (PerkinEImer, Waltham, MA USA).

Cell lines, antibodies and reagents. Yac- 1 cells were cultured in RPMI 1640 (Gibco, Carlsbad, CA USA), supplemented with 10\% FBS, $50 \mu \mathrm{M} \beta$-ME, $100 \mathrm{U} / \mathrm{ml}$ penicillin and $100 \mu \mathrm{g} / \mathrm{ml}$ streptomycin. MEFs were grown in DMEM medium supplemented with $10 \%$ FBS, $50 \mu \mathrm{M} \beta$-ME and $100 \mu \mathrm{M}$ asparagine. Commercial antibodies were mouse mAb against $\beta$-actin (Sigma, St Louis, MO USA), cyt $c$ (BD Pharmingen, San Jose, CA, USA), activated Bax (MAb 6A7, BD Pharmingen), caspase 2, caspase 8 , caspase 9 (Cell signaling, Danvers, MA, USA) rabbit anti-COX IV (Abcam, Cambridge, UK), anti-caspase 3 (Cell signaling), anticaspase 3 (Biomol Research, Plymouth Meeting, PA, USA), Alexa488-conjugated donkey anti-mouse IgG (Molecular Probes, Carlsbad, CA, USA) and HRPconjugate secondary antibodies (Santa Cruz, CA, USA). The ProLong antifade kit and Mitotracker were from Molecular Probes. Caspase inhibitor Z-VAD-FMK and fluorogenic substrates Ac-DEVD-AFC, Z-VDVAD-AFC, Z-IETD-AFC and Ac-LEHDAFC were from Calbiochem (Darmstadt, Germany). The luminescent ATP cell viability assay kit was from Promega (Madison, WI, USA).

Gzms delivering with adenovirus, PFP or SLO. Replication-deficient adenovirus type V (Vector Gene Technology Company, Beijing, China), human PFP purified from YT cells (PFP, from Alexis Biochemicals, San Diego, CA, USA) and SLO (from Sigma-Aldrich) were utilized for delivering Gzms. A total of $100 \mathrm{PFU} / \mathrm{cell}$ of Ad was used to deliver Gzms into target cells as previously reported. ${ }^{21}$ Sublytic concentrations of PFP or SLO were determined to load Gzms into target cells. PFP was used at a final concentration of $150 \mathrm{ng} / \mathrm{ml}$ and SLO was used at $400 \mathrm{ng} / \mathrm{ml}$ for Yac-1 cells. For each experiment, SLO was preactivated by $10 \mathrm{mM}$ DTT at RT for $10 \mathrm{~min}$. Yac-1 Cells $\left(2 \times 10^{5}\right.$ in a final volume of $\left.50 \mu \mathrm{l}\right)$ were incubated with different concentrations of Gzms for the indicated times.

Cytotoxicity assay. Cytotoxicity of LAK cells was tested against Yac-1 target cells in standard ${ }^{51} \mathrm{Cr}$ release assay. Yac- 1 cells $\left(1 \times 10^{6}\right)$ were labeled with $200 \mu \mathrm{Ci}{ }^{51} \mathrm{Cr}$ at $37^{\circ} \mathrm{C}$ for $1 \mathrm{~h}$. After a complete wash, Yac-1 cells were plated at $1 \times 10^{4}$ cells/well. LAK cells were added at the indicated E/T ratios and after $4 \mathrm{~h}$ of incubation, supernatants were harvested and the specific release of ${ }^{51} \mathrm{Cr}$ was measured using MicroBeta counter (PerkinElmer). In some experiments, Yac-1 cells were preincubated with z-VAD-FMK $(100 \mu \mathrm{M})$ at $37^{\circ} \mathrm{C}$ for $30 \mathrm{~min}$. Specific cytotoxicity was calculated as [(sample release - spontaneous release)/(maximum release-spontaneous release)] $\times 100$. Maximum release of target cells was measured after treatment with 2\% TritonX-100. For in vitro delivery of Gzms, Yac-1 cells were treated with Gzms plus Ad and the specific release of ${ }^{51} \mathrm{Cr}$ was assessed as above.
Laser-scanning confocal microscopy. For cyt $c$ assay, cells were seeded overnight and treated as indicated. The treated cells were washed thrice, then fixed with $4 \%$ paraformaldehyde for $1 \mathrm{~h}$ at $4{ }^{\circ} \mathrm{C}$, permeabilized with $0.05 \%$ NP-40 for 20 min and blocked for 30 min with $10 \%$ donkey serum in PBS. Anti-cyt $c$ antibody was added for $1 \mathrm{~h}$ at RT, and stained with Alexa488-conjugated donkey anti-mouse IgG. Slides were mounted and images were visualized with Olympus FV500 laser-scanning confocal microscopy (Tokyo, Japan). The same procedure was used for Bax activation assay except for permeabilizing with $0.2 \%$ Triton X-100.

Transmission electron microscopy. Yac- 1 cells $\left(1 \times 10^{6}\right)$ were treated with $\mathrm{Gzms}$ and $\mathrm{Ad}$ at $37^{\circ} \mathrm{C}$ for $6 \mathrm{~h}$. The cells were washed twice and fixed with $2 \%$ glutaraldehyde on ice for $1 \mathrm{~h}$, then postfixed in $2 \%$ osmium tetroxide. After dehydrating with sequential washes in 50,70,80, 90 and $100 \%$ ethanol, cells were embedded in Spurrs resin. The sections were mounted in copper grids, counterstained with uranyl acetate and lead citrate, then visualized in a JEM-100 CX transmission electron microscopy (Tokyo, Japan). Images were photographed and scanned by Eversmart Jazz + program (Scitex, Israel).

Quantification of ATP content. Total cellular ATP concentration was assessed using a luminescent ATP cell viability assay kit from Promega. Briefly, Yac-1 cells were treated as indicated, washed carefully and then lyzed with $50 \mu \mathrm{l}$ lysis buffer. Luminescence was measured for $10 \mathrm{~s}$ with a luminometer (Model TD20/20, Turner BioSystems, Sunnyvale, CA USA). ATP contents are presented as relative luminescence units (RLU).

Cellular caspase activity assay. Caspase activity was measured under the manufacturer's instruction. Briefly, $4 \times 10^{5}$ Yac-1 cells were treated as indicated, washed twice and lysed with $50 \mu$ l lysis buffer ( $50 \mathrm{mM}$ HEPES, pH 7.4, $100 \mathrm{mM}$ $\mathrm{NaCl}, 0.1 \%$ Chaps, $5 \mathrm{mM}$ DTT, $0.1 \mathrm{mM}$ EDTA). Cellular lysates were harvested and incubated with $30 \mu \mathrm{M}$ caspase substrates at $37^{\circ} \mathrm{C}$. Fluorescence was measured using a Fluoroskan Ascent (Type 374, ThermoLabsystems, Waltham, MA, USA). Data were normalized to the level of blank cells and shown as means \pm S.D.

Cyt $c$ release assay. Cyt $c$ release from mitochondria to cytosol was detected by western blotting. Cells were fractionated with $0.025 \%$ digitonin for $5 \mathrm{~min}$ on ice. Mitochondrial (pellet) and cytosolic (supernatant) fractions were obtained after $5 \mathrm{~min}$ centrifuge at $10000 \times g$.

Oxygen consumption assessment. Cells were treated as indicated and resuspended in a final concentration of $3 \times 10^{6}$ cells $/ \mathrm{ml}$ at TD buffer $(25 \mathrm{mM}$ Tris- $\mathrm{HCl}$, pH 7.4-7.5 $\left.\left(25^{\circ} \mathrm{C}\right), 137 \mathrm{mM} \mathrm{NaCl}, 10 \mathrm{mM} \mathrm{KCl}, 0.7 \mathrm{mM} \mathrm{Na}_{2} \mathrm{HPO}_{4}\right)$. Oxygen consumption was measured using a Respirometer (model RC650, Strathkelvin Instruments, North Lanarkshire, UK). Respiratory rates are designated as $\mathrm{nmol}_{2} / \mathrm{min}^{39}$

DNA fragmentation and nicking assay. Treated Yac-1 cells were harvested and resuspended in a DNA extraction buffer $(100 \mathrm{mM}$ Tris-Cl, $\mathrm{pH} 8.0$, $5 \mathrm{mM}$ EDTA, $0.2 \mathrm{M} \mathrm{NaCl}, 0.5 \%$ SDS and $0.2 \mu \mathrm{g} / \mu \mathrm{l}$ proteinase $\mathrm{K}$ ) for $2 \mathrm{~h}$ at $52^{\circ} \mathrm{C}$. $\mathrm{NaCl}$ was added to a final concentration of $1.5 \mathrm{M}$ to precipitate intact genomic DNA. DNA was then precipitated with standard $\mathrm{EtOH}$ precipitation procedures and resuspended in $1 \times$ TE plus $10 \mu \mathrm{g} / \mathrm{ml}$ RNase $\mathrm{A}$ at $37^{\circ} \mathrm{C}$ for $2 \mathrm{~h}$ and analyzed by $2 \%$ agarose gel electrophoresis. For DNA nicking assay, GzmF-treated cells were lysed with $0.5 \% \mathrm{NP}-40$ lysis buffer and incubated with $5 \mathrm{U}$ Klenow fragment of DNA polymerase I and $10 \mu \mathrm{Ci}{ }^{32} \mathrm{P}$-dATP for $1 \mathrm{~h}$ at $37^{\circ} \mathrm{C}$. Genomic DNA was extracted, washed thoroughly, separated by denaturing alkaline gel electrophoresis and visualized by autoradiograph.

Transmembrane potential and ROS detection. Changes in mitochondrial membrane potential $\left(\Delta \psi_{\mathrm{m}}\right)$ were measured by flow cytometry with $\mathrm{DiOC}_{6}(3)$ (Molecular Probes) at a final concentration of $40 \mathrm{nM}$. Cells were harvested after treatment, washed twice and stained with $\mathrm{DiOC}_{6}(3)$ for flow cytometry analysis. Intracellular ROS production was assessed by incubating cells with $20 \mu \mathrm{M} \mathrm{H}_{2} \mathrm{DCF}$ $\mathrm{DA}$ at $37^{\circ} \mathrm{C}$ for $30 \mathrm{~min}$. Unincorporated dye was removed by completely washing, and cells were then treated as indicated and monitored by flow cytometry.

Generation of LAK cells. For preparation of LAK cells, splenocytes from $\mathrm{BALB} / \mathrm{c}$ mice were purified by the Ficoll-Hypaque density gradient centrifugation separation. Harvested cells were cultured in six-well plates $\left(1 \times 10^{7} /\right.$ well) with complete medium containing 1000 units/ml recombinant human interleukin 2 (rhlL-2). After 5 days, $1 \mathrm{ml}$ fresh medium with rhlL-2 was added for 3 more days of culture. 
Quantitative RT-PCR. Total RNA was isolated using Trizol reagent and reverse-transcribed with Superscript II (Invitrogen, Carlsbad, CA, USA). The mRNA content was measured by the Rotor-Gene 6000 analyzer (Corbett Research, Sydney, Australia). Primers specific for each Gzm used in this study were obtained from the literature. ${ }^{18,40} \mathrm{GzmB}$ sense, 5'-ATCAAGGATCAGCAGCCTGA-3', and antisense, $5^{\prime}$-TGATGTCATTGGAGAATGTCT-3'; GzmF sense, $5^{\prime}$-TGAGG TTTGTGAAAGATAATG- $3^{\prime}$, and antisense, $5^{\prime}$-TCACTGGTGTTGTCCTTATC-3'; 18S rRNA sense, 5'-ACCGCAGCTAGGAATAATGGA- $3^{\prime}$, and antisense, $5^{\prime}$-GCCTCAGTTCCGAAAACCA-3'. Relative mRNA levels were calculated by the comparative cycle threshold method and 18S rRNA was used as the internal control for each sample.

RNA silencing of GzmF. Three pairs of RNA sequences against GzmF for RNAi were designed using BLOCK-iT RNAi Designer (Invitrogen) and cloned into pSuper-puro that expresses $19 \mathrm{nt}$ shRNA. One pair of shRNA sequence that efficiently knocked down the expression of GzmF was used in this study. The sense strand of this sequence was GCACTGGAAGCTCAATGAG. Recombinant adenoviruses were constructed according to the manufacturer's instructions (Stratagene, La Jolla, CA, USA). H1 promoter with shRNA was cloned from pSupershGzmF by PCR and subcloned into an adenoviral pShuttle vector. The verified pShuttle-H1-shGzmF vector was transformed into BJ5183-AD1 cells, and recombinant pAd-H1-shGzmF adenoviral genome was generated. Recombinant shGzmF-expressing adenoviruses (Ad-shGzmF) were produced in Ad293 cells for RNA-silencing experiments. GFP-expressing adenoviruses (Ad-GFP) were generated in the same way, except that it was under the control of CMV promoter. For infection of LAK cells, splenocytes were plated in six-well dishes at $1 \times 10^{7}$ cells per well plus rhlL-2 $(1000 \mathrm{U} / \mathrm{ml})$. At day 5 , Ad-shGzmF or Ad-GFP was added to infect LAK cells at $2000 \mathrm{PFU} / \mathrm{cell}$ and cultured for an additional 3 or 4 days for GzmF silencing. Infection efficiency was monitored using Ad-GFP through flow cytometry or fluorescence microscopy.

Acknowledgements. We thank Dr. Q Hou and $\mathrm{H}$ Zhang, and D Hu and $\mathrm{H}$ Tang for their helpful advice; and CC Liu, L Sun and Y Teng for their technical support. Bid KO MEF is a gift from Dr. A Strasser (The Walter and Eliza Hall Institute of Medical Research, Australia); Bax/Bak DKO MEF is generously provided by Dr. Q Chen (Institute of Zoology, CAS). This work was supported from the National Natural Science Foundation of China (30525005, 30830030, 30772496, 30700126), 863 program (2006AA02Z4C9), 973 programs (2006CB504303, 2006CB910901), the Innovative program (KSCX2-YW-R-42) and the Hundred Talents Program of CAS.

1. Russell JH, Ley TJ. Lymphocyte-mediated cytotoxicity. Annu Rev Immunol 2002; 20: 323-370.

2. Barry M, Bleackley RC. Cytotoxic T lymphocytes: all roads lead to death. Nat Rev Immunol 2002; 2: 401-409.

3. Grossman WJ, Revell PA, Lu ZH, Johnson H, Bredemeyer AJ, Ley TJ. The orphan granzymes of humans and mice. Curr Opin Immunol 2003; 15: 544-552.

4. Thomas DA, Du C, Xu M, Wang X, Ley TJ. DFF45/ICAD can be directly processed by granzyme $B$ during the induction of apoptosis. Immunity 2000; 12: 621-632.

5. Waterhouse NJ, Sedelies KA, Browne KA, Wowk ME, Newbold A, Sutton VR et al. A central role for Bid in granzyme B-induced apoptosis. J Biol Chem 2005; 280: 4476-4482.

6. Lieberman J, Fan Z. Nuclear war: The granzyme A-bomb. Curr Opin Immunol 2003; 15: 553-559.

7. Fan Z, Beresford PJ, Zhang D, Lieberman J. HMG2 interacts with the nucleosome assembly protein SET and is a target of the cytotoxic T-lymphocyte protease granzyme A. Mol Cell Biol 2002; 22: 2810-2820.

8. Johnson H, Scorrano L, Korsmeyer SJ, Ley TJ. Cell death induced by granzyme C. Blood 2003; 101: 3093-3101.

9. Zhao T, Zhang H, Guo Y, Zhang Q, Hua G, Lu H et al. Granzyme K cleaves the nucleosome assembly protein SET to induce single-stranded DNA nicks of target cells. Cell Death Differ 2007; 14: 489-499.

10. Hou Q, Zhao T, Zhang H, Lu H, Zhang Q, Sun L et al. Granzyme H induces apoptosis of target tumor cells characterized by DNA fragmentation and Bid-dependent mitochondrial damage. Mol Immunol 2008; 45: 1044-1055.

11. Lu H, Hou Q, Zhao T, Zhang H, Zhang Q, Wu L et al. Granzyme M directly cleaves inhibitor of caspase-activated DNase (CAD) to unleash CAD leading to DNA fragmentation. $J$ Immunol 2006; 177: 1171-1178.

12. Kelly JM, Waterhouse NJ, Cretney E, Browne KA, Ellis S, Trapani JA et al. Granzyme M mediates a novel form of perforin-dependent cell death. J Biol Chem 2004; 279: 22236-22242.
13. Fellows $E$, Gil-Parrado $S$, Jenne $D E$, Kurschus $F C$. Natural killer cell-derived human granzyme $H$ induces an alternative, caspase-independent cell-death program. Blood 2007; 110: 544-552.

14. Masson D, Tschopp J. A family of serine esterases in lytic granules of cytolytic $T$ lymphocytes. Cell 1987; 49: 679-685.

15. Jenne D, Rey C, Haefliger JA, Qiao BY, Groscurth P, Tschopp J. Identification and sequencing of CDNA clones encoding the granule-associated serine proteases granzymes D, E, and F of cytolytic T lymphocytes. Proc Natl Acad Sci USA 1988; 85: 4814-4818.

16. Sattar R, Ali SA, Abbasi A. Bioinformatics of granzymes: sequence comparison and structural studies on granzyme family by homology modeling. Biochem Biophys Res Commun 2003; 308: 726-735

17. Pham CT, Maclvor DM, Hug BA, Heusel JW, Ley TJ. Long-range disruption of gene expression by a selectable marker cassette. Proc Natl Acad Sci USA 1996; 93: 13090-13095.

18. Revell PA, Grossman WJ, Thomas DA, Cao X, Behl R, Ratner JA et al. Granzyme B and the downstream granzymes $C$ and/or $F$ are important for cytotoxic lymphocyte functions. J Immunol 2005; 174: 2124-2131.

19. Hink-Schauer C, Estebanez-Perpina E, Wihharm E, Fuentes-Prior P, Klinkert W, Bode W et al. The 2.2-A crystal structure of human pro-granzyme $\mathrm{K}$ reveals a rigid zymogen with unusual features. J Biol Chem 2002; 277: 50923-50933.

20. Odake S, Kam CM, Narasimhan L, Poe M, Blake JT, Krahenbuhl $O$ et al. Human and murine cytotoxic $T$ lymphocyte serine proteases: subsite mapping with peptide thioester substrates and inhibition of enzyme activity and cytolysis by isocoumarins. Biochemistry 1991; 30: 2217-2227.

21. Froelich CJ, Orth K, Turbov J, Seth $P$, Gottlieb R, Babior B et al. New paradigm for lymphocyte granule-mediated cytotoxicity. Target cells bind and internalize granzyme $B$, but an endosomolytic agent is necessary for cytosolic delivery and subsequent apoptosis. J Biol Chem 1996; 271: 29073-29079.

22. Zhao T, Zhang H, Guo Y, Fan Z. Granzyme K directly processes bid to release cytochrome $c$ and endonuclease $\mathrm{G}$ leading to mitochondria-dependent cell death. $\mathrm{J}$ Biol Chem 2007; 282: 12104-12111.

23. Leist $M$, Jaattela $M$. Four deaths and a funeral: from caspases to alternative mechanisms. Nat Rev Mol Cell Biol 2001; 2: 589-598.

24. Fan Z, Beresford PJ, Oh DY, Zhang D, Lieberman J. Tumor suppressor NM23-H1 is a granzyme A-activated DNase during CTL-mediated apoptosis, and the nucleosome assembly protein SET is its inhibitor. Cell 2003; 112: 659-672.

25. Heibein JA, Goping IS, Barry M, Pinkoski MJ, Shore GC, Green DR et al. Granzyme B-mediated cytochrome $c$ release is regulated by the $\mathrm{Bcl}-2$ family members Bid and Bax. J Exp Med 2000; 192: 1391-1402.

26. Barry M, Heibein JA, Pinkoski MJ, Lee SF, Moyer RW, Green DR et al. Granzyme B shortcircuits the need for caspase 8 activity during granule-mediated cytotoxic T-lymphocyte killing by directly cleaving Bid. Mol Cell Biol 2000; 20: 3781-3794.

27. Darmon AJ, Ley TJ, Nicholson DW, Bleackley RC. Cleavage of CPP32 by granzyme B represents a critical role for granzyme $B$ in the induction of target cell DNA fragmentation. J Biol Chem 1996; 271: 21709-21712.

28. Kim HE, Du F, Fang M, Wang X. Formation of apoptosome is initiated by cytochrome $c$ induced dATP hydrolysis and subsequent nucleotide exchange on Apaf-1. Proc Natl Acad Sci USA 2005; 102: 17545-17550.

29. Degterev A, Huang Z, Boyce M, Li Y, Jagtap P, Mizushima N et al. Chemical inhibitor of nonapoptotic cell death with therapeutic potential for ischemic brain injury. Nat Chem Biol 2005; 1: 112-119.

30. Kroemer G, Galluzzi L, Vandenabeele P, Abrams J, Alnemri ES, Baehrecke EH et al. Classification of cell death: Recommendations of the Nomenclature Committee on Cell Death 2009. Cell Death Differ 2009; 16: 3-11.

31. Zhang H, Zhong C, Shi L, Guo Y, Fan Z. Granulysin induces cathepsin B release from lysosomes of target tumor cells to attack mitochondria through processing of bid leading to necroptosis. J Immunol 2009; 182: 6993-7000.

32. Wang X, Yang C, Chai J, Shi Y, Xue D. Mechanisms of AIF-mediated apoptotic DNA degradation in Caenorhabditis elegans. Science 2002; 298: 1587-1592.

33. Li LY, Luo $X$, Wang $X$. Endonuclease $G$ is an apoptotic DNase when released from mitochondria. Nature 2001; 412: 95-99.

34. Kroemer G, Galluzzi L, Brenner C. Mitochondrial membrane permeabilization in cell death. Physiol Rev 2007; 87: 99-163.

35. Zamaraeva MV, Sabirov RZ, Maeno E, Ando-Akatsuka Y, Bessonova SV, Okada Y. Cells die with increased cytosolic ATP during apoptosis: a bioluminescence study with intracellular luciferase. Cell Death Differ 2005; 12: 1390-1397.

36. Tsujimoto Y. Apoptosis and necrosis: intracellular ATP level as a determinant for cell death modes. Cell Death Differ 1997; 4: 429-434.

37. Sato T, Machida T, Takahashi S, Murase K, Kawano Y, Hayashi T et al. Apoptosis supercedes necrosis in mitochondrial DNA-depleted Jurkat cells by cleavage of receptorinteracting protein and inhibition of lysosomal cathepsin. J Immunol 2008; 181: 197-207.

38. Ricci JE, Munoz-Pinedo C, Fitzgerald P, Bailly-Maitre B, Perkins GA, Yadava $\mathrm{N}$ et al. Disruption of mitochondrial function during apoptosis is mediated by caspase cleavage of the p75 subunit of complex I of the electron transport chain. Cell 2004; 117: 773-786.

39. Duan S, Hajek P, Lin C, Shin SK, Attardi G, Chomyn A. Mitochondrial outer membrane permeability change and hypersensitivity to digitonin early in staurosporine-induced apoptosis. J Biol Chem 2003; 278: 1346-1353.

40. Getachew Y, Stout-Delgado H, Miller BC, Thiele DL. Granzyme C supports efficient CTLmediated killing late in primary alloimmune responses. J Immunol 2008; 181: 7810-7817. 